\title{
Investigation and analysis of artistic characteristics and charm of Nuo culture in Nanfeng County
}

\author{
Dong Yalin
}

Nanchang Institute of Science \& Technology, Nanchang 330108,China

Key words: regional culture; artistic charm; Nuo masks; Nanfeng ;Nuo culture;

\begin{abstract}
In order to study the regional Nanfeng Nuo culture artistic characteristics and charm, the development history of Nanfeng Nuo Nuo dance costumes, tracing and Nuo mask as a starting point, through field investigation and data acquisition, combined with professional academic works of Nanfeng Nuo culture artistic charm makes comments on the research objective. First discusses the historical status and significance of Nanfeng Nuo culture, and then combined with the method of literature and on-the-spot investigation, the people familiar with the extent of the Nuo culture view of Nuo culture conducted an investigation and analysis of results, the result showed that most of the local residents in Nanfeng County is familiar to Nuo culture, and rarely people think it is feudal superstition, most people regard Nuo culture as a kind of traditional folk culture, which is conducive to the promotion of Nuo culture and heritage. Finally, combined with the development of tourism projects, the art characteristics and promotion of Nuo culture in Nanfeng County are discussed, which provides a valuable reference for the development and promotion of Nuo culture, folk culture and art in Nanfeng county.
\end{abstract}

\section{Introduction}

Nuo, an ancient totem worship spanning more than three thousand years, has developed into a kind of inherent. In addition to exorcism ritual carrier disease. Jiangxi is one of the important publishing areas of Chinese exorcise culture, especially the land.

Located in Nanfeng County of Jiangxi, it retains the imprint of the ancient civilization since the early years of the Western Han dynasty. It records the traces of this unique cultural phenomenon in the course of the years. Based on the study on the basis of Nanfeng Nuo mask and unique charm of the folk art Nuo, dig behind Nuo Nuo culture and spirit of artistic charm. Through the investigation of Nuo culture and art characteristics and regional folk customs, fully aware of the local people of Nuo culture as a traditional cultural identity. Finally, presents the interpretation of the intangible cultural heritage in modern society in the context of the new objective.

\section{The historical position and evaluation of Nanfeng Nuo}

In Jiangxi Nanfeng County, Nuo culture occupies an important position in the popular culture, Nuo culture has integrated many arts and culture, including religious culture, folk culture and art culture, its cultural and artistic forms mainly reflects the farming society a group phenomenon. After inheriting and Simulation of thousands, Nuo culture and not suffered a huge impact, thus kept intact, which is "known as a living fossil of ancient folk dances, plays an important role in the China folk cultural history. In the new China after the founding of Beijing by Nuo containing requirements, to participate in the first session of the National Folk Art Festival, has since received extensive attention. 
Since 1991, many domestic and foreign experts and students conducted a field study in Nanfeng County, including the United States, South Korea and France and other countries arts and cultural institutions, Nanfeng County in 1992 by the Jiangxi Department of Culture named Nuo dance village, intangible cultural heritage in 2006, the first national, among which is the jump dance. 2008 Jiangxi Nanfeng County again won the China folk cultural village of the title, also identified a number of Nuo art heritage, the heritage of people representative obvious. Nanfeng Nuo dance heritage of the original obviously, President of Institute of Nuo opera Mr. Qu Liuyi also gave a high evaluation, he even looked after Nuo awake at night, he felt the Nanfeng County retains very complete farming "when the rough and simple, has an important guiding significance for the study of modern art cultural performance.

Jiangxi is located in the South County is one of the important Chinese distribution of Nuo culture, is an important manifestation of local ethnic culture, the Nuo Nuo mask and so on, and the gap between the reality of modern life is very large, but we love these, and with strong interest to appreciate, because these are things with the ancient area features, combined with local flavor, give us a lot of modern art could give. Nuo fog and Nuo mask are a kind of ancient national culture, which have been handed down for thousands of years. They are traditional inheritance and continuity. Therefore, they are of great value. On the other hand, these things formally handed down a true portrayal of the society, for example, Exorcism Chuyi blessing, this is our modern society needs, the artistic charm has an important guiding significance for the development of the national culture and arts.

\section{Investigation and analysis of artistic characteristics of Nuo culture in Nanfeng County}

In order to study the Nanfeng County of Nuo culture art and folk customs through the dissemination of results, methods of literature and investigation, study the artistic charm and the dissemination effect of Nuo culture, by selecting the typical Nanfeng County and three township as the research object, through access to information and research the research level of understanding of Nanfeng Nuo the results are shown in Table 1.

Table 1 Investigation results of the understanding of Nanfeng Nuo

\begin{tabular}{|c|l|}
\hline The understanding of Nuo culture & Research results $/ \%$ \\
\hline Very familiar & $31 \%$ \\
\hline Probably familiar & $66 \%$ \\
\hline Do not understand & $3 \%$ \\
\hline
\end{tabular}

The research results are shown in Table 1, the higher level of understanding of Nuo culture has occupied $31 \%$ of the total number, for most probably familiar with Nuo culture, occupies $66 \%$ of the total number, only 3\% of people know little of Nuo culture. Through analysis, it is found that Nuo culture has a high degree of local cognition in Nanfeng County, and only a few people do not understand Nuo culture, and Nuo culture has a great influence on the local. In order to further study the artistic charm and regional characteristics of Nuo culture, the views of Nuo culture were investigated and analyzed, and the results shown in Table 2 were obtained.

Table 2 the view and research results of Nuo culture

\begin{tabular}{|c|l|}
\hline Views on Nuo culture & Research results /\% \\
\hline The spirits of flooding and peace & $7 \%$ \\
\hline Feudal superstition & $6 \%$ \\
\hline Do not understand & $2 \%$ \\
\hline Chinese traditional folk custom & $85 \%$ \\
\hline
\end{tabular}


As shown in Table 2, the number of Chinese that Nuo culture is the traditional folk culture, occupies $85 \%$ of the total number, indicating that most of the people is quite recognized for its artistic charm and Nuo culture, only $7 \%$ and $6 \%$ of the people think that Nuo culture is a kind of disease in addition to ensure the safety of the exorcism of feudal superstition, there are $2 \%$ people no understanding of Nuo culture, neutral. This analysis can be seen, along with the development of thousands of years of cultural heritage and modern art, it has been from the original simple dance of God worship and Nuo dance change has Nuo culture as a traditional folk culture of Nuo culture, the high degree of recognition, this is also the reason why the Nuo culture has the charm of folk and regional characteristics.

\section{develop exorcise culture, regional characteristics and charm Tourism}

In order to play the special charm of Nuo culture area, requires a combination of tourism projects, the establishment of Nuo culture own brand items, the traditional regional culture marketing, the use of economic means to set up the stage singing culture, give full play to the charm of Nuo culture on the market pull action. But in the process, do not pay attention to the economic returns, integrity can not destroy the Nuo culture, at the same time to ensure that economic development to the protection of cultural resources for the purpose, so as to give full play to regional characteristics and charm of Nuo culture, Nuo culture which can be long, passed down from generation to generation.

According to the further investigation of Nanfeng County, more than half of the people think that it is feasible to develop the theme of exorcise culture in Nanfeng county. To build the integrated tourism city leisure and cultural experience, make the economic growth driven by tourism, Nuo culture tourism growth, highlighting the "Han Nuo Nanfeng rhyme, humanistic resort, beautiful orange, ecological tourism, Kingdom play Nuo culture in the local folk customs and regional characteristics, which makes Nuo culture to inherit and develop long term.

\section{Conclusion}

In order to artistic characteristics and charm of Nanfeng Nuo culture research and analysis, combined with the historical status and evaluation of Nuo culture, Nuo culture of local people on the familiarity of folk culture, the identity of the research and analysis, analysis of the results, most of the residents in Nanfeng County of Nuo culture has a higher degree of recognition. That is a kind of folk culture, rather than a simple ritual of Exorcism in addition to plague. In order to give full play to the artistic charm of Nuo culture, the inheritance and promotion can be better combined, Nuo culture tourism projects, the promotion of Nuo culture are discussed, provide a new reference for the study of the value development of Nuo culture and Nuo culture.

\section{Acknowledgement}

The work was supported by the general project of art planning project in Jiangxi with the project number YG2015087 and the project name The application of Nuo culture elements in modern dress design Based the example of Nanfeng County in Jiangxi.And the topic direction is Investigation and analysis of artistic characteristics and charm of Nuo culture in Nanfeng County.

\section{Reference}

[1] Zhong Jingui, Yao Qiurong. Century bridge. Thinking of the inheritance and protection of Gelao family of Nuo culture [J]. Bridge of Century,2013 (08). 
[2] exhibition, Chun Lan. Bibliometric analysis of the literature of Nuo culture in China [J]. Journal of Zunyi Normal University,2011 (03).

[3] Zhang Zehong. A brief study of the relationship between Nuo culture and Taoism in the southwest of China. [J]. Ethnic Studies in Guizhou, 2010 (02).

[4] MouXiaomei. Chishui River Basin Gelao Nuo mask art features of [J]. MangZhong, 2012 (15).

[5] Wang Lvzhu, Liu Li,Wuchuan. Carving art really Gelao folk research [J]. Guizhou History Series,2012 (01).

[6] Yang Junchang. Daozheng Nuo's culture and heritage issues - "Daozhen yilao and Miao Autonomous County, Nuo culture" reading[J]. Journal of Southwest University for Nationalities (SOCIAL SCIENCE EDITION),2011 (11).

[7] Yuan Lihui. The environmental attribution of Nuo Nuo culture [J].Everybody,2011 (15).

[8] Shen Lu. Guizhou Nuo opera and Taoism in from the visual angle [J]. Guizhou ethnic studies ,2013 (05).

[9] Liu Xinglu. Review of Chinese Nuo culture since twentieth Century[J]. Journal of Jishou University (SOCIAL SCIENCE EDITION), 2013 (05).

[10] Han Shuang. Analysis of Nuo culture tourism development in Shuangfeng County in southern Sichuan as an example [J]. class Nuo Du Tourisme (second half) 2013 (03).

[11] Zhou Xinjuan, Wang Liping, Nie Meiying. Discussion on the modern value of Nuo culture in Pingxiang [J]. Journal of Pingxiang College,2013 (01).

[12] Yang Yin, Mei Yunqing, Li Qiang. Research on Anhui Nuo culture and eco economic development in Poyang Lake [J]. Fine arts, 2012 (05).

[13] Li Wei, Wan Shaofang. Fusion of Nuo culture and folk belief in Jiangxi[J]. Frontier, 2012 (09).

[14] Huang Zhen. Development history and research course of Jiangxi Nuo [J]. Journal of Huaihua University, 2012 (03).

[15] Li Fan. Exploring the spreading path of graphic symbols in Gan Nuo [J]. Writer,2011 (22). 